TENDENCIAS

Revista de la Facultad de Ciencias

Económicas y Administrativas.

Universidad de Nariño

ISSN-E 2539-0554

Vol. XXIII No. 1 - 1er Semestre 2022

Enero - Junio - Páginas 87-116

\title{
DIVERSIDAD ECONÓMICA REGIONAL Y DESEMPEÑO SOCIOECONÓMICO EN LAS PROVINCIAS DEL ECUADOR (PERÍODO 2014-2018) ${ }^{1}$
}

REGIONAL ECONOMIC DIVERSITY AND SOCIO-ECONOMIC PERFORMANCE IN

THE PROVINCES OF ECUADOR (PERIOD 2014-2018)

\section{DIVERSIDADE ECONÔMICA REGIONAL E DESEMPENHO SOCIOECONÔMICO NAS PROVÍNCIAS DO EQUADOR (PERÍODO 2014-2018)}

Wilson Santiago Izquierdo Rodríguez; Paola Alexandra Carangui Velecela

Maestrando en Desarrollo Local, Universidad Católica de Cuenca. Licenciado en Contabilidad y Auditoría, Escuela Superior Politécnica Ecológica Amazónica, Ecuador. ORCiD: 0000-00022545-3327. E-mail: wilson.izquierdo.14@est.ucacue.edu.ec, Ecuador.

Magíster en Administración de Negocios, Universidad Católica de Cuenca, Ecuador. Docente de la carrera Contabilidad y Auditoría, Universidad Católica de Cuenca. ORCiD: 0000-0002-45526378. E-mail: pcaranguiv@ ucacue.edu.ec, Ecuador.

Recibido: 8 de mayo de 2021

Aprobado: 15 de octubre de 2021

DOI: https://doi.org/10.22267/rtend.222301.184

\footnotetext{
${ }^{1}$ Este artículo es resultado del Proyecto de investigación conducente al grado de Magíster en Desarrollo Local, mención Economía Social y Solidaria, de la Universidad Católica de Cuenca (Ecuador). Los hallazgos, interpretaciones y conclusiones pertenecen a los autores y no representan los puntos de vistas de las instituciones en las cuales participan. Finalmente, los errores restantes y omisiones son de responsabilidad de los autores.
} 


\title{
Resumen
}

El presente artículo tiene como objetivo estimar el efecto de la diversidad económica regional sobre las condiciones socioeconómicas en las provincias del Ecuador, tomando como referencia el período 2014-2018. La investigación es de tipo explicativa, con diseño documental, no experimental, transversal y emplea como métodos de análisis los enfoques analítico-sintético y cuantitativo-empírico. Las estimaciones econométricas efectuadas con datos de corte transversal de las 24 provincias del Ecuador, con el método de Mínimos Cuadrados Ordinarios, sugieren efectos positivos del coeficiente de especialización regional y del índice de concentración sobre la volatilidad observada en el ingreso y en el crecimiento. Así mismo, la especialización regional se asocia con una mayor tasa de pobreza, mientras que hay una relación inversa entre especialización y concentración con la tasa promedio de crecimiento de las provincias. El estudio permitió concluir, en primer lugar, que la planificación del desarrollo exige la reducción de las heterogeneidades productivas que presenta una economía como Ecuador y, en segundo lugar, que los beneficios del desarrollo sólo serán ampliamente percibidos por la población en la medida que las regiones diversifican su actividad económica.

Palabras clave: concentración económica; desarrollo económico; desarrollo regional; estructura económica; geografía económica.

JEL: O11; O18; R11; R12; R58

\begin{abstract}
This article aims to estimate the effect of regional economic diversity on socioeconomic conditions in the provinces of Ecuador, taking as a reference the period 2014-2018. The research is explanatory, with a documentary, non-experimental, cross-sectional design, and uses analytical-synthetic and quantitative-empirical approaches as analysis methods. Econometric estimates made with cross-sectional data from the 24 provinces of Ecuador, using the Ordinary Least Squares method, suggest positive effects of the regional specialization coefficient and the concentration index on the volatility observed in income and growth. Likewise, regional specialization is associated with a higher poverty rate, while there is an inverse relationship between specialization and concentration with the average growth rate of the provinces. The study allowed to conclude, firstly, that development planning requires the reduction of the
\end{abstract}


productive heterogeneities that an economy such as Ecuador presents and, secondly, that the benefits of development will only be widely perceived by the population to the extent that the regions diversify their economic activity.

Keywords: economic concentration; economic development; regional development; development strategy; economic structure; development theory.

JEL: O11; O18; R11; R12; R58

\section{Resumo}

Este artigo tem como objetivo estimar o efeito da diversidade econômica regional nas condições socioeconômicas das províncias do Equador, tomando como referência o período 2014-2018. A pesquisa é explicativa, com desenho documental, não experimental, transversal, e utiliza como métodos de análise as abordagens analítico-sintética e quantitativo-empírica. Estimativas econométricas feitas com dados transversais das 24 províncias do Equador, utilizando o método dos mínimos quadrados ordinários, sugerem efeitos positivos do coeficiente de especialização regional e do índice de concentração sobre a volatilidade observada na renda e no crescimento. Da mesma forma, a especialização regional está associada a uma maior taxa de pobreza, enquanto existe uma relação inversa entre especialização e concentração com a taxa média de crescimento das províncias. O estudo permitiu concluir, em primeiro lugar, que o planejamento do desenvolvimento requer a redução das heterogeneidades produtivas que uma economia como a do Equador apresenta e, em segundo lugar, que os benefícios do desenvolvimento só serão amplamente percebidos pela população na medida em que as regiões diversificarem seus atividades económicas.

Palavras-chave: concentração econômica; desenvolvimento econômico; desenvolvimento regional; estratégia de desenvolvimento; estrutura econômica; teoria do desenvolvimento.

JEL: O11; O18; R11; R12; R58

\section{Introducción}

Existe un renovado interés en la teoría del desarrollo por entender qué factores se hallan detrás del desempeño económico y las condiciones de vida en un espacio geográfico. En ese sentido, se han suscitado cambios de paradigma en el campo del desarrollo, pasando el enfoque de análisis 
desde un ámbito macroeconómico hacia lo subnacional, apuntando hacia la búsqueda de respuestas a la problemática socioeconómica desde una óptica particular, en la que también los gobiernos locales y regionales emprenderían acciones y medidas conducentes a mejores resultados socioeconómicos dentro de sus áreas de actuación. En este caso, el subsistema regional centra la atención del proceso mismo del desarrollo económico y social.

Como resultado, uno de los problemas que caracteriza el desarrollo de las regiones dentro de un país tiene que ver con la dinámica de sus actividades económicas y estructura productiva. Más allá de lo tentador que resulta la hipótesis de convergencia para países en desarrollo respecto al nivel de ingreso de los países ricos (Molero, 2014), los fenómenos regionales y el proceso de desarrollo integral de un país demanda la atención directa sobre las regiones que lo conforman, en específico la diversidad económica y las condiciones socioeconómicas dentro del espacio regional Campolina (2003).

La comparación no es tanto respecto al contexto internacional, sino más bien se enfoca la cuestión del desarrollo desde el prisma de las regiones, con el propósito de que la expansión de las fuerzas productivas del país y los resultados socioeconómicos sean uniformemente distribuidos entre todas las regiones. En ese contexto, un país como Ecuador puede mejorar su ingreso nacional y desempeño, aunque regionalmente cabe la posibilidad que se presenten polos, con estructuras productivas heterogéneas, concentración de la producción en actividades de tipo extractivista repercutiendo en la calidad de vida de los habitantes en las regiones y con un impacto ambiental negativo.

Por lo tanto, se debe ahondar en las diferencias en el desempeño socioeconómico y en la relación entre la actividad económica regional y los resultados sociales y económicos que se obtienen en las localidades y regiones, tomando en cuenta que el proceso de desarrollo socioeconómico de un país no se efectúa de forma sincrónica y uniforme a lo largo de sus regiones y territorio. Para subsanar esas limitaciones iniciales, Dissart (2003) reseña la propuesta posterior de tomar en cuenta la diversidad económica regional como una meta del desarrollo en sí mismo. 
Así pues, y de acuerdo a Dissart, por diversidad se entiende la variedad de actividades económicas que refleja diferencias en la estructura económica (2003: 424). Se sostiene que si no existe diversidad regional no se puede lograr un desempeño óptimo en el plano social y económico entre las poblaciones, como lo demuestran las realidades de países como el Ecuador, donde las regiones con mayor diversidad económica tienden a ostentar mejores indicadores socioeconómicos y las desigualdades territoriales van acompañadas de externalidades negativas (Urdaneta y Borgucci, 2021), socavando la posibilidad de un desarrollo equilibrado (Mendieta \& Pontarollo, 2016).

El análisis regional arroja ciertos patrones en la estructura productiva y diversidad económica. Tomando en cuenta un indicador de la actividad económica, por sectores y actividades, existen regiones cuyos resultados en la producción se encuentran repartidos en un amplio espectro de actividades económicas, más o menos uniformemente, mientras que otras regiones cuentan con un bajo número de industrias y sectores. Contrastar esto en Ecuador resulta interesante, pues hay una amplia aceptación en los últimos años en promover un perfil económico y productivo más dinámico y diverso en las regiones, con el objeto que estas cuenten con el motor endógeno que permita corregir la problemática socioeconómica que muchas arrastran desde hace tiempo. Esto se refleja en los esfuerzos de cambio en la matriz productiva, concepto que se retoma en la planificación nacional, con el propósito de acelerar el desarrollo del país, sobre la base de la diversificación productiva, tanto a nivel nacional como entre regiones (Díaz et al., 2019).

Si bien existe una amplia literatura de la economía regional, que estudian las diferencias en cuanto a sectores productivos en las regiones y en relación a las características que definen su condición socioeconómica, como el ingreso, el crecimiento y la pobreza (Bonilla, 2008; Davies y Tonts, 2009; Del Campo et al., 2008; Guisán y Cardim-Barata, 2003; Heilig, 2006; Pede, 2013; Silveira, 2007), existe una ausencia de estudios en el caso ecuatoriano que relacionen diversidad económica regional con indicadores concretos de desempeño socioeconómico a nivel provincial. Así, en el marco del debate teórico y los principales hechos estilizados de la diversidad económica regional del Ecuador, se desarrolla esta investigación cuyo objetivo consiste en estimar el efecto de la diversidad económica regional sobre las condiciones socioeconómicas en las provincias del Ecuador, tomando como referencia el período 2014-2018. Esta investigación 
es importante para entender la dinámica del desarrollo a nivel local y brinda implicaciones relevantes para la formulación de políticas que apunten hacia subsistemas políticos de menor nivel que la nación.

\section{Fundamentación teórica}

Evidentemente, el desarrollo económico de las naciones es posible en situaciones en que la diversidad de actividades productivas es redituable. Por tanto, la existencia de organizaciones prósperas y variadas dentro de un territorio es expresión significativa de la expansión económica y de, posiblemente, la mejora de la calidad de vida de sus ciudadanos. Pero, la diversidad económica y el desarrollo a nivel regional no es un asunto que solamente atañe a la política económica del gobierno a nivel nacional; muy por el contrario, es un asunto de cada vez mayor interés para las regiones y localidades, debido sobre todo a que el desarrollo económico nacional no es simétrico ni goza de una sincronía entre todas las regiones en el tiempo.

Dado lo antes expuesto, es interesante abordar la relación entre diversidad económica regional y desempeño socioeconómico desde una perspectiva de carácter teórico. En ese sentido, es menester comenzar precisando que la diversidad económica regional está fuertemente relacionada con el desarrollo económico regional y esta, a su vez, con la teoría del desarrollo. Por su parte, el desempeño económico y social se abordará por medio de una serie de propuestas que, en algunos casos, implicarán el desarrollo de indicadores de gestión económico-social.

El desarrollo económico se podría conceptualizar como los esfuerzos para mejorar el bienestar social y la calidad de vida de una comunidad mediante la creación o mantenimiento de puestos de trabajos, ingresos y la base fiscal (Raupp y Raupp, 2018). Para Mora (2006), la teoría del desarrollo no es una disciplina unificada que tuvo su inicio en la segunda mitad de la década de los años 40, con la aparición de las llamadas teorías de la modernización, en donde prevaleció la idea de que desarrollo equivalía a crecimiento económico, siendo relevante la idea de “crecimiento por etapas" (Rostow, 1960).

Sobre la base de la modernización surgen, entre 1947 y 1982, los modelos y políticas de industrialización por sustitución de importaciones, donde el Estado jugaría un papel crítico 
(Prebisch, 1950). No obstante, este esquema enfrentó serios problemas tales como: la lenta transformación productiva, la mala distribución de la renta, la desarticulación estructural en la industria o fallas en la protección arancelaria. A lo anterior, se agrega la inestabilidad de los mercados de materias primas y sus efectos en la balanza, el aumento de endeudamiento, agravando la situación fiscal (déficits) y monetaria (inflación galopante).

La crítica al esquema de industrialización por sustitución de importaciones tuvo dos desafíos teóricos, las teorías heterodoxas y la vuelta de la visión liberal. La primera se conoce como teoría de la dependencia con la idea de que el subdesarrollo es consecuencia del modo de producción capitalista y que en el tercer mundo se ha constituido en un obstáculo para el desarrollo. La segunda se asocia a la irrupción neoclásica que comenzó a mediados de los años 70 del siglo XX, enfoque que propuso la apertura de los mercados y preparar a la economía para abatir los desequilibrios estructurales por medio de una serie de recomendaciones de política económica conocidas como Consenso de Washington, ideas basadas en los aportes en crecimiento económico exógeno y endógeno (Lucas, 1988; Romer, 1986; Solow, 1956). Junto a estos últimos planteamientos neoclásicos surge la propuesta del neoinstitucionalismo (Hoff y Stiglitz, 2002; North, 1990; Williamson, 1985). Este enfoque busca arreglos como instituciones políticas y económicas inclusivas (Acemoglu y Robinson, 2013), mediante la aplicación de criterios de optimalidad (Campos, 1999), para fomentar los incentivos económicos que posibilitan el desarrollo económico y social de las naciones.

La capacidad analítica de los enfoques institucionalistas ha sido extendida al ámbito espacial, para el conocimiento y la interpretación de fenómenos geográficos como las diferencias en niveles de desarrollo entre regiones de un país (Caballero, 2009). De ese modo, la cuestión del desarrollo regional se encuentra relacionada con la geografía humana, que a su vez queda determinada por elementos institucionales propios de cada espacio dentro de un país, como pueden ser regiones o provincias, que tienen sus propias creencias, historias o arreglos informales. Esos elementos o marco institucional propio de cada región configuran distintos costos de transacción, como información asimétrica, a nivel regional o espacial, repercutiendo en la estructura y actividad económica, así como en el desarrollo socioeconómico de cada territorio. Así, el concepto de región y sus diferencias ganan importancia por cuanto los costos de 
transacción no son nulos en el espacio, como lo demuestra la evidencia histórica y empírica (Caballero, 2009), existiendo costos positivos a nivel regional.

Por otro lado, Comisión Económica para América Latina y el Caribe (CEPAL) (1990) considera que las causas de la crisis económica y el limitado crecimiento y desarrollo se deben a la condición de ser economías rentísticas, que también se extiende al caso específico de regiones. De manera alterna, Fajnzylber (1983) y CEPAL (2006) exponen que, entre 1940 y 1960, la industrialización era el paradigma del desarrollo, bajo los preceptos de las llamadas "leyes de Kaldor-Verdoom", pero en la década de los años 70 se generó un cuestionamiento a la industrialización, generándose una crisis general de confianza en la estrategia, por lo que se ofreció un enfoque alternativo a la perspectiva de la apertura económica, basada en una transformación productiva con equidad (CEPAL, 1990).

Pero, el desarrollo económico debe ser regional y local y en tal sentido los principales aportes vienen de la teoría de la causación acumulativa (Myrdal, 1957), el concepto de especialización flexible (Piore y Sabel, 1993), la Nueva Geografía Económica (Krugman, 1998), la revolución de los rendimientos crecientes (Fujita et al., 2000) y la Nueva Economía Institucional (Caballero, 2009). Por su parte, Veltz (1996) propone la red-archipiélago de regiones y, desde el punto de vista de las políticas regionales, justifica la existencia de generaciones de políticas de desarrollo regional. Además, Merchand (2007) agrega que la circularidad del capital en regiones y ciudades mejora sus ventajas comparativas. En un ámbito más local, se encuentran los aportes de Becattini (1987) y Brusco (2008) con la idea de "Distretto industriale", idea similar al cluster (Porter, 1998) o la teoría de la ubicación (Krugman, 1998). Por último, Caballero (2009) ponen el acento en el carácter espacial de las instituciones, y cómo los costos de transacción positivos determinan las características económicas de las regiones.

En cuanto a la categoría diversidad, European Central Bank (ECB) (2021) la considera como la diversidad en las estructuras económicas o productivas relacionada con la importancia relativa de las diferentes actividades dentro del Producto Interno Bruto e indica el grado de especialización de un sistema económico. Consideran Siegel et al. (1995) que por diversidad debe entenderse una situación o estado de desemejanza, diferencia y variedad. Ahora bien, para Moncayo (2003), 
los aspectos territoriales se han convertido en referentes de los procesos socioeconómicos, es decir, el desarrollo regional implica mejores condiciones de vida. Como consecuencia, Merchand (2007) habla de "equidad interregional" como fin de una política pública regional, mientras tanto que North (1955) y Rosales y López (2008) consideran que el desarrollo regional depende de la capacidad exportadora en cada región.

Si bien estos últimos autores no hacen mención directa al tema de la diversidad, es claro que en la medida que una región presente mayor diversidad económica puede ser más eficiente en las mismas, aprovechar economías de escala intra industrias, incrementar la innovación, el aprendizaje y el conocimiento, reducir costos y, eventualmente, competir en los mercados externos. Mayor valor agregado entre todas las actividades de producción puede generar las condiciones para que una región exporte valor agregado, incremento su productividad y con ello promocione el desarrollo desde adentro. En ese aspecto, Rosales y López (2008) señalan que "la diversificación se vuelve un paso necesario" (p.163), y la estructura económica define la posibilidad o no de que una región se vuelva dinámica y logre avances en materia de desarrollo, idea que ha recibido soporte empírico (Davies y Tonts, 2009; Pede, 2013; Plummer et al., 2017).

En cuanto al concepto de condiciones socioeconómicas, de acuerdo con Jama y Cornejo (2015), las mismas se determinan y evalúan por medio de un conjunto de indicadores económicosociales aplicados a una región: ingresos y gastos de hogares; consumo de la población; peso de la deuda pública y gasto social en el país; evaluación de los indicadores relativos a los Objetivos del Milenio; entre otros. Estos mismos autores sostienen que habitualmente las condiciones socioeconómicas dependen o se ven afectadas por las condiciones macroeconómicas de un país.

Desde el punto de vista de Rello y Saavedra (2013), la transformación estructural de las regiones puede brindar resultados heterogéneos. Toda transformación estructural involucra cambios en la dinámica económica y productiva, que implica el paso de sociedades basadas en la agricultura de subsistencia, hacia etapas con mayor dinamismo económico, caracterizado por una diversidad de actividades económicas con elevada productividad y costos de transacción nulos. En la medida que la diversidad sea mayor, hay más posibilidades que la transformación estructural arroje beneficios para las condiciones socioeconómicas de las poblaciones. Los resultados 
comparativos pueden ser duales o heterogéneos, porque hay regiones que se dan más hacia la diversificación, el progreso y crecimiento de sectores productivos de arrastre, tanto de otras actividades como de localidades aledañas, mientras que habrá regiones con subsectores económicos atrasados y sin posibilidad de emprender una dinámica productiva que autogenere crecimiento y bienestar.

\section{Metodología}

La presente investigación es de tipo explicativa, con diseño documental, no experimental y transversal, y emplea como métodos de análisis los enfoques analítico-sintético y cuantitativoempírico, siguiendo la perspectiva de conjunción de métodos de Bernal (2010). En ese orden de ideas, el método analítico-sintético se utilizará como enfoque para la fundamentación teórica.

Por su parte, el enfoque cuantitativo-empírico se refleja en el diagnóstico de la estructura productiva, para identificar las medidas de diversidad y la realidad socioeconómica de las provincias (diagnóstico situacional) y su tratamiento con estadísticas descriptivas, así como la medición de los efectos y la relación empírica (validación) entre las variables. En este último caso, y a partir de los datos disponibles y técnicas, se procederá a la cuantificación de valores que representan las variables de estudio en la realidad concreta analizada, contrastándose la validación de los efectos por medio de un set de modelos de regresión con datos de corte transversal que involucran a las variables a través de cierta especificación (ecuación 1) y su estimación por Mínimos Cuadrados Ordinario (MCO):

$$
Y_{i}=\beta_{0}+\beta_{1} X_{i}+u_{i} \operatorname{con} i=1,2, \ldots, 24 \text { provincias }
$$

Las observaciones de las variables para cada $i$ son presentadas como un promedio del período $T$ (2014-2018). La recopilación de estadísticas se realiza desde fuentes secundarias, como lo son bases de datos del Banco Central del Ecuador [BCE] y del Instituto Nacional de Estadísticas y Censos [INEC], complementada con cálculos propios. La población está conformada por las 24 provincias ecuatorianas y la delimitación temporal cubre el lapso 2014-2018.

Para la medición de la diversidad económica, la variable independiente en el modelo de regresión, se parte del análisis de la estructura productiva de cada región, en concreto estudiando 
la distribución del Valor Agregado Bruto (VAB) por sectores económicos en las 24 provincias, información disponible en las Cuentas Provinciales provistas por el BCE. Partiendo de ello, se calcula el Coeficiente de Especialización regional (CE) con la ecuación (2), arrojando una estructura compuesta por 24 coeficientes, uno para cada provincia $r$, en cada uno de los cinco años que comprende el período 2014-2018.

$$
Q_{r}=\frac{1}{2} * \sum_{i}\left|\frac{V_{i r}}{\sum_{i} V_{i r}}-\frac{\sum_{r} V_{i r}}{\sum_{i} \sum_{r} V_{i r}}\right|
$$

Donde $Q_{r}$ es el coeficiente de especialización (CE) regional, el cual refleja las características de la estructura económica de la región $r$, si presenta especialización relativa cuando el indicador se aproxima a uno (1) o diversidad relativa si más bien se aproxima a cero (0). En la ecuación (2), $\mathrm{V}$ es una variable económica de interés, por ejemplo, el VAB, con lo cual puede conocerse la distribución o estructura económica de la región. De ese modo, $\mathrm{V}_{\text {ir }}$ representa el VAB del sector $i$ en la región $r$ de un período, mientras que el denominador que lo acompaña recoge el VAB total de la región, la suma de los valores agregados de cada actividad dentro de la región $r$. Otra medida de diversidad es provista por lo que la literatura conoce como mediciones equiproporcionales o de entropía (Pede, 2013; Wagner, 2000), como el Índice Hirschman Herfindhal (IHH), para conocer qué tanta concentración por sectores presenta la producción de una región, a través del VAB de sus actividades o sectores, mismo que se muestra en la ecuación (3):

$$
I H H=\sum_{i}\left(\frac{s_{i r}}{s_{r}}\right)^{2}
$$

Donde el índice igual a cero indica mínima concentración de la producción por sectores. Si es exactamente uno entonces hay máxima concentración en la variable con la cual se va a medir la distribución de la actividad económica de cada región. Por último, valores entre 0,1-0,18 reflejan moderada concentración, y aquellos por encima de 0,18 indican elevada concentración. Por último, para representar las condiciones socioeconómicas, que representarán la variable dependiente en el modelo de regresión transversal (1), se emplearán diferentes indicadores, asociados al ingreso, el crecimiento y la pobreza. 


\section{Resultados}

\section{Estructura productiva y realidad socio económica de las provincias del Ecuador}

La figura 1 muestra el porcentaje del Valor Agregado Bruto (VAB) de las provincias respecto al VAB nacional en cada uno de los años. La ponderación refleja la estructura productiva por regiones del Ecuador, en términos relativos, mostrando lo aportado por cada provincia al producto nacional. La última columna de la tabla muestra la participación media de 2014-2018 para cada provincia.

En los cinco años, el VAB de las provincias de Guayas y Pichincha significaron en promedio $26,47 \%$ y $27,12 \%$, respectivamente del VAB ecuatoriano. Otras provincias como Manabí $(6,41 \%)$, Azuay $(5,09 \%)$ y Orellana $(4,83 \%)$ tuvieron una participación destacable en el contexto de la estructura nacional, aunque en el caso de Orellana pudo estar determinada por el desempeño del sector petrolero más que por un cambio estructural en su economía, en cuyo caso otras actividades habrían ganado peso, contribuyendo al crecimiento sostenido de esta región.

\section{Tabla 1}

$V A B$ de cada provincia como porcentaje del VAB total nacional

\begin{tabular}{|c|c|c|c|c|c|c|}
\hline Provincia & 2014 & 2015 & 2016 & 2017 & 2018 & Promedio \\
\hline Azuay & 4,61 & 5,18 & 5,14 & 5,16 & 5,35 & 5,09 \\
\hline Bolívar & 0,50 & 0,60 & 0,62 & 0,65 & 0,64 & 0,60 \\
\hline Cañar & 0,97 & 1,11 & 1,10 & 1,16 & 1,07 & 1,08 \\
\hline Carchi & 0,66 & 0,74 & 0,71 & 0,68 & 0,66 & 0,69 \\
\hline Chimborazo & 1,68 & 2,02 & 2,12 & 1,96 & 1,86 & 1,93 \\
\hline Cotopaxi & 1,64 & 1,88 & 1,83 & 1,89 & 1,95 & 1,84 \\
\hline El Oro & 3,44 & 3,58 & 3,41 & 3,57 & 3,57 & 3,51 \\
\hline Esmeralda & 2,22 & 2,74 & 3,17 & 3,14 & 3,09 & 2,87 \\
\hline Galápagos & 0,21 & 0,22 & 0,24 & 0,25 & 0,25 & 0,24 \\
\hline Guayas & 25,39 & 26,52 & 27,21 & 26,59 & 26,65 & 26,47 \\
\hline Imbabura & 1,93 & 2,04 & 1,95 & 1,90 & 1,93 & 1,95 \\
\hline Loja & 1,74 & 2,00 & 1,93 & 1,80 & 1,78 & 1,85 \\
\hline Los Ríos & 3,43 & 3,86 & 3,81 & 3,79 & 3,56 & 3,69 \\
\hline Manabí & 5,68 & 6,08 & 6,50 & 6,40 & 6,07 & 6,15 \\
\hline Morona Santiago & 0,42 & 0,49 & 0,49 & 0,52 & 0,51 & 0,49 \\
\hline Napo & 0,34 & 0,40 & 0,57 & 0,49 & 0,46 & 0,45 \\
\hline Orellana & 8,64 & 3,77 & 2,90 & 4,05 & 4,67 & 4,80 \\
\hline Pastaza & 1,01 & 0,67 & 0,59 & 0,65 & 0,71 & 0,73 \\
\hline Pichincha & 26,79 & 27,50 & 27,57 & 27,20 & 26,58 & 27,13 \\
\hline
\end{tabular}




\begin{tabular}{crrrrrr} 
Santa Elena & 1,33 & 1,36 & 1,24 & 1,40 & 1,55 & 1,38 \\
Santo Domingo & 1,70 & 1,96 & 1,98 & 1,94 & 2,04 & 1,92 \\
Sucumbíos & 2,84 & 1,97 & 1,71 & 1,55 & 1,89 & 1,99 \\
Tungurahua & 2,58 & 3,00 & 2,88 & 2,94 & 2,87 & 2,85 \\
Zamora Chinchipe & 0,27 & 0,31 & 0,31 & 0,29 & 0,30 & 0,30 \\
Nacional & $\mathbf{1 0 0 , 0 0}$ & $\mathbf{1 0 0 , 0 0}$ & $\mathbf{1 0 0 , 0 0}$ & $\mathbf{1 0 0 , 0 0}$ & $\mathbf{1 0 0 , 0 0}$ & $\mathbf{1 0 0 , 0 0}$ \\
\hline
\end{tabular}

Fuente: cálculos propios (2021).

La desproporción relativa entre el tamaño de las economías regionales de las provincias de Pichincha y Guayas con respecto al resto es una manifestación de las desigualdades territoriales dentro del país. Sin embargo, se debe ahondar en la estructura y distribución del valor generado por actividades en cada provincia, habida cuenta que, en valores absolutos, si bien el tamaño del $\mathrm{VAB}$ es una condición necesaria para describir las desigualdades, no explica todo el fenómeno en estudio. La condición suficiente es provista por el análisis de la diversidad económica, inclusive en provincias de menor tamaño relativo en cuanto a VAB total.

El caso más resaltante de especialización intrarregional está presente en la provincia Orellana donde el 90,83\% de su VAB acumulado 2014-2018 correspondió a la actividad explotación de minas y canteras, mientras que el resto de actividades presentó una participación media irrisoria. De hecho, al comparar con la participación en el agregado nacional, la señalada actividad muestra un peso de $6,46 \%$ en el VAB nacional, considerablemente inferior a la condición que ocupa en la economía de Orellana.

Una caracterización, en cierta forma parecida, experimenta la economía de Los Ríos, la cual presenta casi $41 \%$ de su VAB acumulado sólo en la actividad de agricultura (predominando el cultivo de café, cacao y banano, mismos que se destinan en mayor medida para exportación), y el resto de su valor agregado (59\%) está distribuido en el resto de actividades. Así mismo, la agricultura también es relevante en provincias como Bolívar (22,85\% de su VAB total), Carchi $(27,40 \%)$, Cotopaxi $(25,27 \%)$, El Oro $(25,38 \%)$ y Esmeraldas $(27,83 \%)$. Por otro lado, manufacturas ocupa una participación significativa en Guayas y Pichincha, como antes se dijo, pero también en Azuay, Esmeraldas, Manabí y Santa Elena. La participación media de esta actividad en estas últimas cuatro provincias se encuentra por encima de la media nacional $(15,21 \%)$, indicando una especialización interregional en esta actividad, que puede ser relevante para la dinámica de las provincias. 
En contrapartida, actividades de servicios, como administración pública, es relevante en las provincias de menor tamaño agregado como algunas de las ubicadas en el oriente del país (Morona Santiago, 14,85\%; Napo, 14,18\%; y Zamora Chinchipe, 16,42\%), a la par que la participación media de la actividad dentro del VAN nacional durante el lapso 2014-2018 ascendió a 7,17\%. Otro caso sobresaliente es la actividad de alojamiento y servicios de comida, asociada a la demanda de servicios turísticos, principalmente en Galápagos donde la mencionada actividad representó $11,26 \%$ del VAB de esa provincia en todo el período, muy por encima tanto de la media nacional $(2,25 \%)$ como del más cercano competidor relativo en dicha actividad (Napo con 3,95\%).

El diagnóstico de la estructura económica permite identificar patrones de especialización o diversificación relativa a nivel regional. Dos indicadores de región son útiles para conocer la diversidad regional, como expresión de la estructura productiva y cuyos efectos se quiere evaluar sobre las condiciones socioeconómicas de las provincias en Ecuador. La primera herramienta es el coeficiente de especialización (CE), que permite conocer el grado relativo de similitud de la estructura económica de la provincia $r$ en comparación al patrón de la economía nacional. La segunda es un índice de concentración del tipo Hirschman-Herfindhal (IHH), para conocer el grado de concentración del VAB por actividades dentro de una región geográfica especifica.

La Tabla 2 dispone de los valores estimados para el coeficiente de especialización regional. Estos resultados un valor promedio de 0,29 para 120 observaciones de la variable que cubren el período 2014-2018, con una desviación estándar de 0,15 aproximadamente, la cual refleja una relativamente menor dispersión de los datos.

\section{Tabla 2}

Indicadores de región: coeficiente de especialización por provincia

\begin{tabular}{cccccccc}
\hline Provincia & $\mathbf{2 0 1 4}$ & $\mathbf{2 0 1 5}$ & $\mathbf{2 0 1 6}$ & $\mathbf{2 0 1 7}$ & $\mathbf{2 0 1 8}$ & $\begin{array}{c}\text { Promedio } \\
\text { prov. }\end{array}$ & $\begin{array}{c}\text { Std. } \\
\text { Dev. }\end{array}$ \\
\hline Azuay & 0,202 & 0,165 & 0,152 & 0,157 & 0,174 & 0,170 & 0,020 \\
Bolívar & 0,341 & 0,316 & 0,301 & 0,311 & 0,323 & 0,318 & 0,015 \\
Cañar & 0,311 & 0,236 & 0,224 & 0,229 & 0,226 & 0,245 & 0,037 \\
Carchi & 0,322 & 0,310 & 0,322 & 0,289 & 0,312 & 0,311 & 0,013 \\
Chimborazo & 0,230 & 0,191 & 0,199 & 0,200 & 0,179 & 0,200 & 0,019
\end{tabular}




\begin{tabular}{cccccccc} 
Cotopaxi & 0,294 & 0,255 & 0,242 & 0,281 & 0,265 & 0,268 & 0,020 \\
El Oro & 0,259 & 0,224 & 0,218 & 0,240 & 0,244 & 0,237 & 0,016 \\
Esmeralda & 0,300 & 0,267 & 0,303 & 0,288 & 0,282 & 0,288 & 0,014 \\
Galápagos & 0,353 & 0,317 & 0,337 & 0,354 & 0,372 & 0,347 & 0,021 \\
Guayas & 0,160 & 0,128 & 0,119 & 0,121 & 0,117 & 0,129 & 0,018 \\
Imbabura & 0,190 & 0,150 & 0,157 & 0,164 & 0,177 & 0,168 & 0,016 \\
Loja & 0,239 & 0,202 & 0,201 & 0,196 & 0,227 & 0,213 & 0,019 \\
Los Ríos & 0,406 & 0,362 & 0,367 & 0,367 & 0,387 & 0,378 & 0,019 \\
Manabí & 0,199 & 0,167 & 0,153 & 0,161 & 0,155 & 0,167 & 0,019 \\
Morona Santiago & 0,296 & 0,277 & 0,290 & 0,284 & 0,276 & 0,285 & 0,009 \\
Napo & 0,297 & 0,295 & 0,400 & 0,338 & 0,340 & 0,334 & 0,043 \\
Orellana & 0,838 & 0,828 & 0,800 & 0,837 & 0,841 & 0,829 & 0,017 \\
Pastaza & 0,558 & 0,422 & 0,419 & 0,428 & 0,484 & 0,462 & 0,060 \\
Pichincha & 0,218 & 0,195 & 0,185 & 0,203 & 0,203 & 0,201 & 0,012 \\
Santa Elena & 0,270 & 0,248 & 0,204 & 0,251 & 0,251 & 0,244 & 0,024 \\
Santo Domingo & 0,254 & 0,230 & 0,194 & 0,216 & 0,250 & 0,229 & 0,025 \\
Sucumbíos & 0,626 & 0,483 & 0,467 & 0,400 & 0,472 & 0,490 & 0,083 \\
Tungurahua & 0,184 & 0,146 & 0,137 & 0,143 & 0,157 & 0,153 & 0,019 \\
Zamora Chinchipe & 0,330 & 0,289 & 0,281 & 0,274 & 0,268 & 0,288 & 0,024 \\
\hline Promedio año & 0,320 & 0,279 & 0,278 & 0,281 & 0,291 & & \\
Std. Dev. & 0,155 & 0,145 & 0,146 & 0,144 & 0,151 & & \\
\hline
\end{tabular}

Fuente: cálculos propios (2021).

De los indicadores de región que miden la diversidad regional en cuanto a su estructura productiva, el CE promedio de cada provincia en 2014-2018 ilustra las amplias disparidades a nivel regional, según la estructura productiva que las economías muestran, donde coexisten distintos grados de especialización y diversificación regional. En tal sentido, sólo 5 provincias (casi $21 \%$ de la muestra) tienen un coeficiente que recoge un grado favorable de diversificación en sus actividades económicas, a través de la medida empleada del VAB. La mayor parte de las provincias, 16 en total, cuentan con un promedio ubicado entre 0,2 y 0,4 , dejando ver ciertos grados intermedios de especialización, mientras que 3 provincias si presentan una marcada especialización relativa en la composición de su VAB por actividades.

En un extremo, la provincia Orellana ostenta un coeficiente de especialización regional por encima de 0,8 en todos los años, con una media de 0,829 para 2014-2018, y una desviación estándar baja, sugiriendo no sólo una mayor especialización regional relativa, si no también pocas señales de cambio en la estructura productiva de esta provincia. De acuerdo con la evidencia previa, el CE ilustra que provincias como Azuay $(0,17)$, Guayas $(0,13)$, Imbabura 
$(0,17)$, Manabí $(0,17)$ y Tungurahua $(0,15)$ presentan valores promedios más cercanos a cero, revelando una dinámica de diversidad relativa en sus estructuras económicas.

En general, las provincias orientales (que conforman la región Amazónica) muestran CE elevados, como Morona Santiago $(0,29)$, Napo $(0,33)$, Pastaza $(0,46)$ y Zamora Chinchipe $(0,29)$, es decir, ello revela una composición de actividades que tiende a ser más especializada respecto a la estructura nacional. Además, Bolívar $(0,32)$, Carchi $(0,31)$, Galápagos $(0,35)$ y Los Ríos $(0,38)$ destacan por tener valores medios de especialización por encima del promedio nacional. En cualquier caso, se recalca que el valor promedio de todas las observaciones es considerado como relativamente alto, sugiriendo un grado intermedio de especialización de la economía ecuatoriana.

Para evaluar la concentración del VAB por actividad económica en las provincias, la Tabla 3 contiene los valores estimados del IHH durante los cinco años que cubren el lapso 2014-2018. Conforme a los resultados, la mayor parte de las provincias tienen niveles moderados de concentración del $\mathrm{VAB}$, mientras que la mayor evidencia de concentración de la producción se presenta en las provincias de Los Ríos $(0,22)$, Orellana $(0,80)$, Pastaza $(0,28)$ y Sucumbíos $(0,34)$. De nuevo, Orellana emerge como la provincia con mayor especialización regional y elevado grado de concentración de la producción según el VAB por actividades.

\section{Tabla 3}

Indicadores de región: IHH por provincia

\begin{tabular}{cccccccc}
\hline Provincia & $\mathbf{2 0 1 4}$ & $\mathbf{2 0 1 5}$ & $\mathbf{2 0 1 6}$ & $\mathbf{2 0 1 7}$ & $\mathbf{2 0 1 8}$ & $\begin{array}{c}\text { Promedio } \\
\text { prov. }\end{array}$ & $\begin{array}{c}\text { Std. } \\
\text { Dev. }\end{array}$ \\
\hline Azuay & 0,112 & 0,110 & 0,109 & 0,105 & 0,110 & 0,109 & 0,002 \\
Bolívar & 0,129 & 0,131 & 0,127 & 0,137 & 0,137 & 0,132 & 0,005 \\
Cañar & 0,119 & 0,114 & 0,115 & 0,117 & 0,109 & 0,115 & 0,004 \\
Carchi & 0,140 & 0,151 & 0,151 & 0,134 & 0,148 & 0,145 & 0,007 \\
Chimborazo & 0,108 & 0,113 & 0,119 & 0,110 & 0,102 & 0,110 & 0,006 \\
Cotopaxi & 0,144 & 0,133 & 0,132 & 0,134 & 0,133 & 0,135 & 0,005 \\
El Oro & 0,135 & 0,129 & 0,115 & 0,127 & 0,126 & 0,127 & 0,007 \\
Esmeralda & 0,178 & 0,165 & 0,175 & 0,176 & 0,167 & 0,172 & 0,006 \\
Galápagos & 0,124 & 0,125 & 0,133 & 0,139 & 0,149 & 0,134 & 0,010 \\
Guayas & 0,128 & 0,123 & 0,124 & 0,121 & 0,119 & 0,123 & 0,003 \\
Imbabura & 0,107 & 0,108 & 0,106 & 0,106 & 0,108 & 0,107 & 0,001
\end{tabular}




\begin{tabular}{|c|c|c|c|c|c|c|c|}
\hline Loja & 0,108 & 0,111 & 0,110 & 0,109 & 0,115 & 0,111 & 0,003 \\
\hline Los Ríos & 0,228 & 0,216 & 0,212 & 0,206 & 0,222 & 0,217 & 0,009 \\
\hline Manabí & 0,114 & 0,115 & 0,119 & 0,119 & 0,113 & 0,116 & 0,003 \\
\hline Morona Santiago & 0,108 & 0,108 & 0,111 & 0,105 & 0,103 & 0,107 & 0,003 \\
\hline Napo & 0,109 & 0,118 & 0,150 & 0,117 & 0,121 & 0,123 & 0,016 \\
\hline Orellana & 0,911 & 0,774 & 0,710 & 0,792 & 0,816 & 0,801 & 0,073 \\
\hline Pastaza & 0,465 & 0,221 & 0,184 & 0,236 & 0,309 & 0,283 & 0,111 \\
\hline Pichincha & 0,121 & 0,121 & 0,117 & 0,119 & 0,121 & 0,120 & 0,002 \\
\hline Santa Elena & 0,132 & 0,139 & 0,122 & 0,134 & 0,138 & 0,133 & 0,007 \\
\hline Santo Domingo & 0,120 & 0,118 & 0,114 & 0,114 & 0,120 & 0,117 & 0,003 \\
\hline Sucumbíos & 0,559 & 0,311 & 0,287 & 0,239 & 0,312 & 0,342 & 0,125 \\
\hline Tungurahua & 0,106 & 0,106 & 0,104 & 0,102 & 0,099 & 0,103 & 0,003 \\
\hline Zamora Chinchipe & 0,115 & 0,117 & 0,116 & 0,110 & 0,110 & 0,113 & 0,003 \\
\hline $\begin{array}{c}\text { Ecuador } \\
\text { (Nacional) }\end{array}$ & 0,097 & 0,098 & 0,098 & 0,096 & 0,095 & 0,097 & 0,001 \\
\hline Promedio año & 0,192 & 0,166 & 0,161 & 0,163 & 0,171 & & \\
\hline Std. Dev. & 0,190 & 0,138 & 0,124 & 0,140 & 0,149 & & \\
\hline
\end{tabular}

Fuente: cálculos propios (2021).

Ahora bien, al tomar en consideración la dispersión de los datos observados para cada provincia, sobresale los valores bajos que adopta la desviación estándar en todos los casos, como indicativo de la poca variabilidad que tiene el IHH en cada provincia. De ese modo, no hay tendencia de que cambie la situación de concentración, manteniéndose más o menos los patrones de estructura productiva en las economías regionales.

En lo que concierne a las condiciones socioeconómicas de las provincias, las mismas son evaluadas mediante un conjunto de indicadores que reflejan aspectos económicos y la pobreza. Conforme a lo señalado, para el ámbito económico se describen algunas características de las diferencias regionales en nivel de ingreso por habitante, crecimiento económico, volatilidad del crecimiento, mientras que los aspectos sociales son reflejados en indicadores de pobreza.

Se calculó el monto (en USD) del VAB por habitante de la provincia $r$, como el cociente de su $\mathrm{VAB}$ respecto a la población total que dispuso. En este caso, la estimación es la variable proxy del ingreso per cápita en la región $r$ en el período estudiado. La Figura 1 refleja el ingreso per cápita promedio en cada provincia del país. En ese sentido, el promedio en el panel agrupado es de 5.778 dólares estadounidenses, sin embargo, es claro que la trayectoria de las provincias petroleras como Orellana, Sucumbíos y, en menor medida, Pastaza, elevan sustancialmente la 
media global. Así mismo, provincias como Pichincha, Galápagos, Guayas y Azuay tienen un ingreso per cápita elevado en comparación al resto de provincias. La diferencia estriba en que el primer grupo de provincias mencionada tienen una alta desviación estándar o variabilidad en sus datos, mientras que el segundo grupo presenta niveles más estables en sus observaciones.

\section{Figura 1}

Ingreso per cápita por provincia, promedio 2014-2018

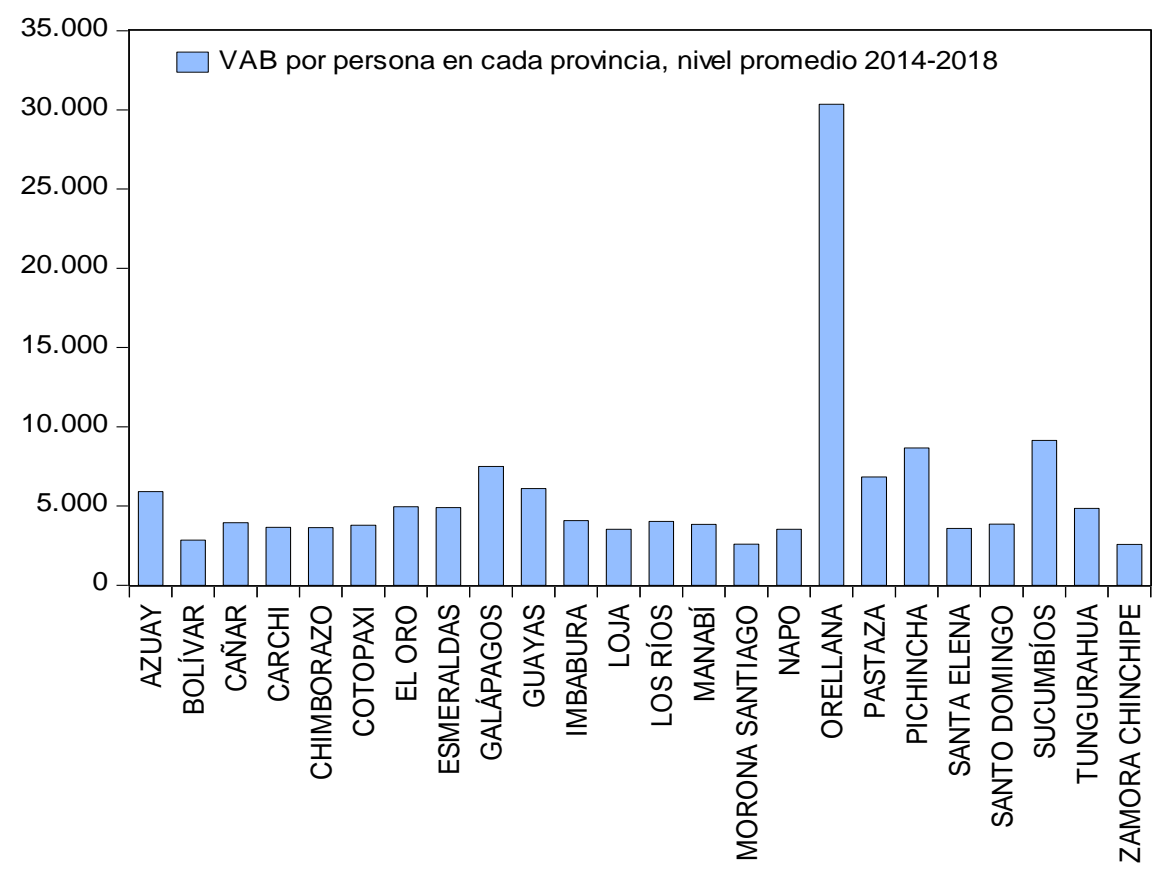

Fuente: elaboración de los autores en Eviews 9 (2021).

La distribución de frecuencias del ingreso per cápita promedio indica que 12 provincias, el 50\% de las provincias del país, tuvieron un ingreso per cápita de entre 2-4 mil USD en promedio durante el lapso. También se ve la dispersión de los datos al ubicar que una sola provincia (Orellana) tuvo un ingreso medio por habitante que es más de siete veces el tamaño máximo del primer rango. De hecho, el promedio de Orellana es tres veces mayor al promedio de su más inmediato seguidor en la distribución (Sucumbíos) y casi cuatro veces el de las provincias con estructuras productivas más diversas y con menos concentración económica como Pichincha y Guayas.

Por el contrario, el crecimiento económico medio muestra otra perspectiva de las diferencias entre las regiones, corrigiendo el sesgo que se presenta con la variable ingreso per cápita. Así, la 
Tabla 4 contiene los datos de la variación interanual en el VAB por habitante como aproximación al crecimiento económico de cada provincia en el período.

Los datos ilustran distintas trayectorias y desempeños en la variación de cada provincia, siendo los casos más agudos observados en las provincias petroleras (Orellana, Pastaza, Sucumbíos y Loja), mismas que presentan fuertes caídas interanuales con una alta variabilidad, reflejo de la inconsistencia en el crecimiento económico debido a la alta exposición o dependencia del mercado petrolero, siendo sus crecimientos medios $-13,4 \%,-10,15 \%,-12,85 \%$ y $-0,04$, respectivamente. En contraparte, pocas provincias disfrutaron de crecimiento económico positivo en todos los años. A ese respecto, Galápagos y, en menor medida, Azuay, Bolívar y Esmeraldas ostentan los mejores desempeños, según el valor promedio y la variabilidad. El crecimiento medio de Galápagos si bien no es el más alto si es más estable junto al de Azuay, lo cual representa un crecimiento más sostenido en el período, a diferencia de otras economías regionales.

\section{Tabla 4}

Crecimiento económico en las provincias del Ecuador, 2014-2018

\begin{tabular}{crrrrrrr}
\hline Provincia & $\mathbf{2 0 1 4}$ & $\mathbf{2 0 1 5}$ & $\mathbf{2 0 1 6}$ & $\mathbf{2 0 1 7}$ & $\mathbf{2 0 1 8}$ & $\begin{array}{c}\text { Promedio } \\
\text { prov. }\end{array}$ & $\begin{array}{c}\text { Std. } \\
\text { Dev. }\end{array}$ \\
\hline Azuay & 3,82 & 4,69 & $-1,38$ & 3,01 & 4,68 & 2,97 & 2,53 \\
Bolívar & 5,30 & 12,83 & 3,56 & 8,15 & $-0,14$ & 5,94 & 4,88 \\
Cañar & $-1,14$ & 7,02 & $-1,83$ & 7,53 & $-7,08$ & 0,90 & 6,26 \\
Carchi & 9,83 & 6,42 & $-3,97$ & $-0,90$ & $-0,61$ & 2,15 & 5,74 \\
Chimborazo & 12,53 & 12,42 & 5,08 & $-4,76$ & $-3,30$ & 4,40 & 8,28 \\
Cotopaxi & 2,58 & 7,31 & $-3,24$ & 6,46 & 4,75 & 3,57 & 4,22 \\
El Oro & 7,87 & $-2,53$ & $-5,02$ & 7,55 & 1,67 & 1,91 & 5,81 \\
Esmeralda & 15,01 & 14,46 & 14,18 & 1,92 & $-0,11$ & 9,09 & 7,51 \\
Galápagos & 4,21 & 0,17 & 7,15 & 4,00 & 2,49 & 3,60 & 2,55 \\
Guayas & 6,23 & $-2,30$ & 2,17 & 0,51 & 1,71 & 1,66 & 3,09 \\
Imbabura & 4,95 & $-0,93$ & $-4,97$ & 0,47 & 3,09 & 0,52 & 3,82 \\
Loja & $-1,13$ & 7,54 & $-3,18$ & $-3,74$ & 0,30 & $-0,04$ & 4,53 \\
Los Ríos & 8,80 & 5,52 & $-1,60$ & 2,29 & $-4,53$ & 2,10 & 5,35 \\
Manabí & 3,45 & 0,66 & 6,73 & 1,79 & $-3,32$ & 1,86 & 3,69 \\
Morona Santiago & 4,52 & 8,32 & $-0,86$ & 7,04 & $-1,85$ & 3,43 & 4,59 \\
Napo & 5,24 & 7,50 & 34,24 & $-12,06$ & $-5,59$ & 5,87 & 17,75 \\
Orellana & $-2,71$ & $-89,74$ & $-26,66$ & 36,43 & 15,67 & $-13,40$ & 48,60 \\
Pastaza & $-7,90$ & $-49,91$ & $-14,22$ & 12,19 & 9,08 & $-10,15$ & 24,85 \\
Pichincha & 10,32 & $-4,43$ & $-0,56$ & 1,05 & $-1,20$ & 1,04 & 5,56
\end{tabular}




\begin{tabular}{crrrrrrr}
\hline & & & & & & & \\
Santa Elena & 2,76 & $-4,71$ & $-10,53$ & 14,01 & 10,80 & 2,47 & 10,28 \\
Santo Domingo & $-9,22$ & 6,95 & 0,44 & 0,58 & 5,94 & 0,94 & 6,42 \\
Sucumbíos & $-17,00$ & $-44,43$ & $-15,19$ & $-7,76$ & 20,13 & $-12,85$ & 23,10 \\
Tungurahua & 4,06 & 8,39 & $-3,94$ & 5,15 & $-0,85$ & 2,56 & 4,92 \\
Zamora Chinchipe & 2,78 & 9,49 & $-1,27$ & $-7,60$ & 6,39 & 1,96 & 6,69 \\
\hline Ecuador & $\mathbf{5 , 2 0}$ & $\mathbf{- 6 , 6 9}$ & $\mathbf{- 0 , 4 5}$ & $\mathbf{2 , 7 6}$ & $\mathbf{1 , 4 6}$ & $\mathbf{0 , 4 6}$ & $\mathbf{4 , 4 9}$ \\
(Nacional) & 3,13 & $-3,30$ & $-1,04$ & 3,47 & 2,42 & & \\
\hline Promedio año & 7,09 & 24,16 & 11,14 & 9,37 & 6,53 & & \\
Std. Dev. & & & & & &
\end{tabular}

Fuente: Cálculos propios (2021).

La tasa media de crecimiento de cada provincia revela diferencias en las experiencias de crecimiento en los cinco años estudiados. Estos patrones de crecimiento disparejos entre las provincias se presentan junto a las diferencias en las estructuras productivas y en los grados de diversidad relativa y concentración que a nivel de actividades económicas presentan.

Con respecto a la dimensión social del desarrollo, se ilustran a continuación las principales características de las provincias del Ecuador en un grupo de indicadores que intenta capturar parcialmente, dada la limitación de la información disponible, las diferencias regionales en condiciones socioeconómicas que influyen en los niveles de vida y bienestar. Para ello, se presentan en la Figura 2 los valores medios del período en dos medidas de la pobreza.

En relación a la pobreza como reflejo de las condiciones socioeconómicas, los indicadores en la figura reflejan que, generalmente, la pobreza está presente en Ecuador en diferentes grados a lo largo de todas las provincias. En cuanto a la pobreza por Necesidades Básicas Insatisfechas (NBI), el promedio entre las 24 provincias alcanzó 36,7\%, abarcando un rango que va desde un mínimo de 10,9\% en Pichincha, hasta una tasa máxima de 56,3\% en Sucumbíos. Incluso, esta última provincia llegó a presentar una tasa de pobreza por NBI de 62,8\% en el año 2016. Por su parte, apenas 3 provincias dispusieron de una tasa de pobreza por NBI en el rango 10-20\%. El resto, presentan valores por encima del $20 \%$, incluso cuatro regiones con tasas superiores a $50 \%$. 


\section{Figura 2}

Pobreza en las provincias del Ecuador, promedio 2014-2018

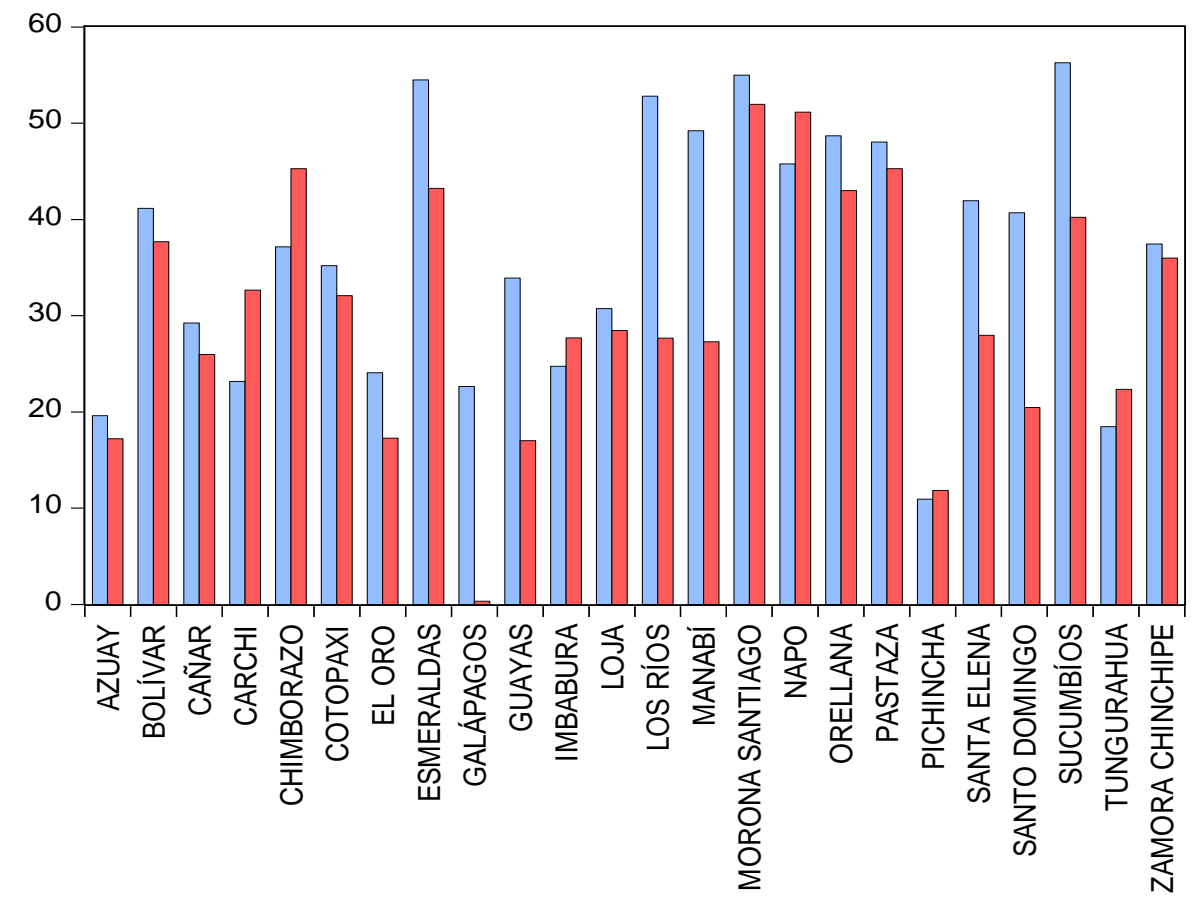

Pobreza por NBI (\%) en cada provincia, promedio de 2014-2018

Pobreza por Ingreso (\%) en cada provincia, promedio de 2014-2018

Fuente: elaboración de los autores en Eviews 9 (2021).

Por su parte, la pobreza por ingreso arroja una tasa promedio de 22,7\% para Ecuador en el período, mientras que la media de las 24 provincias es de 30,4\%, sugiriendo de nuevo una amplia variabilidad entre el grupo observado. En efecto, la tasa más baja es presentada por Galápagos (0,4\% como promedio de 2014-2018), mientras que la mayor tasa se observa en Morona Santiago con 51,9\% de incidencia de la pobreza por ingreso entre sus habitantes. Así mismo, las provincias muestran trayectorias con amplia variabilidad, persistiendo valores altos en Bolívar, Chimborazo, Cotopaxi, Esmeraldas, Los Ríos, Manabí, Morona Santiago, Napo, Orellana, Pastaza, Santa Elena, Santo Domingo y Sucumbíos.

\section{Efectos de la diversidad económica regional en las condiciones socioeconómica}

Los efectos que tiene la diversidad económica sobre las condiciones socioeconómicas observadas en las provincias del Ecuador se miden mediante un conjunto de regresiones. Se llevaron a cabo diferentes ejercicios econométricos donde la variable dependiente es algún 
indicador de las condiciones socioeconómicas, entre ellos, el nivel de ingreso per cápita (en logaritmo), la tasa de variación del ingreso per cápita, como medida del crecimiento, la desviación estándar de la serie tasa de variación del ingreso per cápita, como indicador de la volatilidad de las economías regionales en el período, la tasa de pobreza por NBI y la tasa de pobreza por ingreso como medidas de la pobreza, siendo estas dos últimas la que reflejan las condiciones sociales.

En efecto, la Tabla 5 contiene el conjunto de resultados hallados por MCO para la medición de los efectos de las medidas de diversidad productiva sobre las condiciones socioeconómicas promedios del período 2014-2018. El análisis diagnóstico sugiere que las diferencias entre provincias son mayores que las variaciones que las mismos presentan en el período; dicho de otro modo, hay menos variabilidad en las series de tiempo del panel, razón por la cual se estiman los modelos con 24 observaciones, construidas con los valores promedios de las variables para cada provincia en 2014-2018.

\section{Tabla 5}

Efectos de la diversidad productiva sobre las condiciones socioeconómicas

\begin{tabular}{clrrrrrr}
\hline $\begin{array}{c}\text { Estructura } \\
\text { productiva }\end{array}$ & \multicolumn{7}{c}{ Condiciones socioeconómicas } \\
\hline \multirow{2}{*}{ Diversidad } & $\begin{array}{l}\text { Efectos } \\
\text { sobre: }\end{array}$ & $\begin{array}{r}\text { In(Ingreso } \\
\text { pc) }\end{array}$ & $\begin{array}{r}\text { D.E } \\
\text { Ingreso } \\
\text { pc }\end{array}$ & $\begin{array}{r}\text { Crec. } \\
\text { Econ. }\end{array}$ & Volatilidad Pobr_NBI Pobr_ingr \\
\hline \multirow{2}{*}{ Constante } & Coef. & 7,785 & 3,608 & 8,441 & $-9,012$ & 24,323 & 19,938 \\
\cline { 2 - 9 } & t-stat & 38,891 & 28,359 & 6,580 & $-4,542$ & 4,873 & 5,264 \\
\hline \multirow{2}{*}{ CE } & Coef. & $\mathbf{2 , 3 8 1}$ & $\mathbf{7 , 0 6 8}$ & $\mathbf{- 2 5 , 8 9 9}$ & $\mathbf{6 2 , 8 8 7}$ & $\mathbf{4 2 , 7 9 8}$ & $\mathbf{3 6 , 1 6 8}$ \\
\cline { 2 - 9 } & $\begin{array}{r}t \text {-stat } \\
\text { R2 }\end{array}$ & 3,777 & 12,008 & $-5,267$ & 7,309 & 3,076 & 4,468 \\
\hline & R2 ajust. & 0,446 & 0,733 & 0,487 & 0,807 & 0,231 & 0,169 \\
\hline & $\begin{array}{l}\text { Prob(F- } \\
\text { stat) }\end{array}$ & 0,000 & 0,000 & 0,000 & 0,000 & 0,017 & 0,046 \\
\hline & DW stat & 1,999 & 1,939 & 1,651 & 2,154 & 2,178 & 2,141 \\
\hline & $\begin{array}{l}\text { LM test } \\
\text { prob. }\end{array}$ & 0,808 & 0,657 & 0,394 & 0,541 & 0,641 & 0,885 \\
\hline & $\begin{array}{l}\text { White test } \\
\text { prob. }\end{array}$ & 0,685 & 0,073 & 0,039 & 0,193 & 0,994 & 0,379 \\
\hline & JB prob. & 0,744 & 0,118 & 0,999 & 0,301 & 0,634 & 0,497 \\
\hline
\end{tabular}




\begin{tabular}{|c|c|c|c|c|c|c|c|}
\hline Concentración & $\begin{array}{l}\text { Efectos } \\
\text { sobre: }\end{array}$ & $\begin{array}{r}\ln \text { (Ingreso } \\
\text { pc) }\end{array}$ & $\begin{array}{r}\text { D.E } \\
\text { ingreso } \\
\text { pc }\end{array}$ & $\begin{array}{l}\text { Crec. } \\
\text { Econ. }\end{array}$ & Volatilidad & Pobr_NBI & Pobr_ingr \\
\hline \multirow{2}{*}{ Constante } & Coef. & 7,972 & 4,452 & 5,786 & $-1,907$ & 30,913 & 25,860 \\
\hline & $t$-stat & 91,048 & 2,376 & 7,057 & $-1,247$ & 7,585 & 5,511 \\
\hline \multirow{9}{*}{ IHH } & Coef. & 2,942 & 7,059 & $-28,424$ & 65,155 & 34,056 & 26,712 \\
\hline & $t$-stat & 19,620 & 10,126 & $-5,950$ & 36,117 & 2,242 & 2,389 \\
\hline & $\mathrm{R} 2$ & 0,676 & 0,725 & 0,582 & 0,858 & 0,145 & 0,091 \\
\hline & R2 ajust. & 0,661 & 0,712 & 0,563 & 0,852 & 0,106 & 0,050 \\
\hline & $\begin{array}{l}\text { Prob(F- } \\
\text { stat) }\end{array}$ & 0,000 & 0,000 & 0,000 & 0,000 & 0,060 & 0,151 \\
\hline & DW stat & 1,743 & 1,952 & 1,869 & 1,985 & 2,185 & 2,051 \\
\hline & $\begin{array}{l}\text { LM test } \\
\text { prob. }\end{array}$ & 0,920 & 0,752 & 0,822 & 0,070 & 0,612 & 0,797 \\
\hline & $\begin{array}{l}\text { White test } \\
\text { prob. }\end{array}$ & 0,562 & 0,017 & 0,000 & 0,137 & 0,969 & 0,708 \\
\hline & JB prob. & 0,367 & 0,886 & 0,176 & 0,002 & 0,602 & 0,988 \\
\hline
\end{tabular}

Nota: Se corrigió previamente heteroscedasticidad por el método Newey-West.

Fuente: estimaciones de los autores en Eviews 9 (2021).

Para la diversidad o especialización relativa, de acuerdo al CE regional, se midió un efecto positivo y significativo estadísticamente $(2,38)$ sobre el logaritmo natural del nivel de ingreso per cápita promedio de las provincias, resultado diferente al signo esperado a priori, pues arroja que, en promedio, un mayor nivel de CE regional influye positivamente en el ingreso que disfrutan en las regiones; de manera tal que, las provincias con mayor $\mathrm{CE}$ tienen un mayor ingreso per cápita. En este caso, la posible razón a este resultado se encuentra en que las provincias que tienen mayor CE regional son principalmente aquellas donde prevalece la producción de bienes como el petróleo, de forma que, ante un contexto externo favorable, su nivel de ingreso puede elevarse de forma sustancial, aunque la provincia sea especializada.

Al considerar la desviación estándar en el logaritmo del ingreso per cápita, como indicador de la volatilidad del ingreso, se reflejan los efectos esperados, puesto que el signo del coeficiente estimado en la regresión asociado a la variable exógena es positivo, recogiendo evidencia que comprueba una mayor volatilidad del ingreso en las provincias que tienen un mayor $\mathrm{CE}$ regional. Al considerar la tasa promedio de crecimiento económico como variable dependiente se halló que, como media, existe un efecto inverso y estadísticamente significativo que va del CE 
regional promedio a la tasa de crecimiento promedio de las provincias. En ese sentido, una décima adicional en el $\mathrm{CE}$ tiene un efecto negativo equivalente a casi 2,6 puntos porcentuales en la tasa de crecimiento promedio. Por lo tanto, conforme aumenta la especialización relativa, en una décima adicional, se espera que las provincias presenten una reducción de 2,6 puntos porcentuales en su crecimiento medio.

Del mismo modo, el efecto del CE regional sobre la desviación estándar del crecimiento medio del período, como medida de la volatilidad, es directo y estadísticamente significativo. Una décima adicional en el CE genera 6,2 puntos porcentuales adicionales en la desviación estándar del crecimiento promedio de una provincia. En concreto, un mayor nivel de especialización relativa no solo hace que la provincia típica tenga menor crecimiento medio, respecto a sus pares que tengan diversificación relativa, sino que también tiene efectos en la estabilidad del crecimiento, haciendo que la provincia presente un crecimiento más volátil.

Los efectos de la especialización relativa sobre la pobreza señalan lo esperado a priori, puesto que una décima adicional en el CE tendría un efecto directo de casi 4,3 puntos porcentuales sobre la tasa de pobreza por NBI y de 3,6 puntos porcentuales adicionales en la tasa de pobreza por ingreso. De modo que, en promedio, las provincias más especializadas presentan mayores tasas de pobreza, y una décima adicional en el CE aumentaría la tasa de pobreza promedio.

Desde el punto de vista estadístico, las regresiones del CE regional sobre las condiciones socioeconómicas son robustas, y conservan las propiedades de residuos no autocorrelacionados, homoscedásticos y normalidad. Además, se destaca la alta bondad de ajuste en el caso de los efectos del CE sobre las volatilidades del ingreso y del crecimiento.

Por otro lado, al considerar el grado de concentración del VAB por actividades, conforme una provincia tiene mayor concentración a su vez presenta un nivel de ingreso per cápita más elevado. De nuevo, se impone las condiciones de las provincias con mayor concentración, debido a la característica de su principal actividad económica. No obstante, el coeficiente estimado en los casos de la regresión que involucra a la volatilidad del ingreso, el crecimiento promedio y la volatilidad del crecimiento, sugiere que una mayor concentración genera los efectos esperados, 
positivos en los casos de las volatilidades del ingreso y del crecimiento y negativo sobre el crecimiento medio. Es decir, las provincias con mayor concentración promedio en el período presentan, como promedio, mayor volatilidad y menor crecimiento.

Por cada décima adicional en el IHH, la provincia típica puede ver reducida su tasa media de crecimiento en 2,8 puntos porcentuales y la volatilidad de este crecimiento se puede incrementar en 6,5 puntos porcentuales. Estos vínculos fueron significativos desde el punto de vista estadístico, y los modelos estimados conservan las principales propiedades de la regresión clásica. Las altas bondades de ajuste indican que una fracción significativa de la variabilidad muestral exhibida por las variables dependientes es bien explicada por las diferencias en cuanto a IHH.

Para finalizar, la regresión transversal con información de las 24 provincias del Ecuador, empleando promedios del período 2014-2018, sugiere efectos positivos del nivel de concentración en las provincias sobre la tasa media observada de pobreza tanto por NBI como por ingresos. Sin embargo, estos últimos resultados deben tomarse con cautela, debido al bajo coeficiente de determinación y a la significancia conjunta del modelo.

\section{Conclusiones}

Abordar los desequilibrios económicos a nivel regional es uno de los mayores retos en desarrollo económico que enfrentan actualmente los países. Las distintas estructuras productivas que presentan las regiones de un país terminan generando significativas diferencias en las condiciones de vida que disfrutan sus habitantes.

Ecuador no escapa a tal realidad, siendo que algunas de sus provincias, como Guayas, Pichincha y Azuay, ostentan una diversidad económica relativa, mientras que otras, como el caso de Orellana y Pastaza, son más especializadas respecto a la estructura nacional. Las primeras tres provincias mencionadas manifiestan un mayor espectro de actividades productivas, siendo manufactura, construcción, comercio, actividades profesionales e inmobiliarias, las más representativas, pero sin menoscabo de la participación del resto; en un caso opuesto, la actividad explotación de minas y canteras en la provincia Orellana presentó una participación de 90,26\% 
en el VAB de la provincia en el año 2018, lo que refleja una significativa especialización relativa, sobre el resto de actividades, limitando su desarrollo económico y social.

Bajo esas condiciones, se indagó en torno a la temática, a través de la estimación de los efectos de la diversidad económica regional sobre las condiciones socioeconómicas de las provincias del Ecuador. Los resultados confirman que las provincias con mayor especialización relativa tienen una más alta volatilidad promedio en la evolución de su ingreso per cápita, así como en el ritmo de crecimiento; así mismo presentan mayores tasas de pobreza y menor crecimiento medio en el período estudiado, en comparación a las provincias con más diversificación relativa.

Estos resultados son relevantes para el éxito de la política de cambio en la matriz productiva del Ecuador. El estudio permite concluir, en primer lugar, que la planificación del desarrollo exige la reducción de las heterogeneidades productivas que presenta una economía como Ecuador y, en segundo lugar, que los beneficios del desarrollo sólo serán ampliamente percibidos por la población en la medida que las regiones diversifican la actividad económica. Si bien las medidas sociales adoptadas por las autoridades son valiosas en sí misma, la solución integral para mejorar el bienestar en las regiones, sin agudización de las diferencias entre las mismas, debe incorporar planes de estímulo económico a nuevas actividades con alto valor agregado y productividades.

\section{Referencias}

(1) Acemoglu, D. y Robinson, J. (2013). Por qué fracasan los países. Los orígenes del poder, la prosperidad y la pobreza. (1ra. Edición en español), Barcelona-España, Edit. Deusto.

(2) Becattini, G. (1987). Mercati y forze locali. Il Distretto industriale. Bologna: Il Mulino.

(3) Bernal, C. (2010). Metodología de la investigación. Administración, economía, humanidades y ciencias sociales. Pearson Educación. Colombia, 320p.

(4) Bonilla, L. (2008). Diferencias regionales en la distribución del ingreso en Colombia. Banco de la República, Centro de Estudios Económicos Regionales, Documentos de trabajo sobre Economía Regional No. 108, diciembre 2008. 
(5) Brusco, S. (2008). I distretti industriali: Lezioni per lo Sviluppo. Una lettera e novi saggi (1990-2002), a cura di A. Natali, M. Russo e G. Solinas. Bologna: Il Mulino.

(6) Caballero, G. (2009). El papel de las instituciones en la geografía humana: un enfoque desde la nueva economía institucional. Economía, Sociedad y Territorio, IX(29), 1-31.

(7) Campolina, C. (2003). Repensando la cuestión regional brasileña: tendencias, desafíos y caminos. EURE, 29(88), 29-53. http://dx.doi.org/10.4067/S0250-71612003008800002.

(8) Campos, N. (1999). Context is everything: measuring institutional change in transition economies. Working Paper. CERGE-EI, Czech Republic.

(9) Comisión Económica para América Latina (CEPAL). (1990). Transformación productiva con equidad. La tarea prioritaria de América Latina y el Caribe en los años noventa. Santiago de Chile, Chile.

(10) Comisión Económica para América Latina (CEPAL). (2006). Fernando Fajnzylber: una visión renovadora del desarrollo de América Latina. Santiago de Chile, Chile.

(11) Davies, A. \& Tonts, M. (2009). Economic diversity and regional socioeconomic performance: An empirical analysis of the Western Australian Grain Belt. Geographical Research, 48(3), 223-234.

(12) Del Campo, C., Monteiro, C. \& Oliveira, J. (2008). The European regional policy and the socio-economic diversity of European regions: a multivariate analysis. European Journal of Operational Research, 187, 600-612.

(13) Díaz, N., Mora, L. y Durán, M. (2019). Las bases del cambio de la matriz productiva en Ecuador (2006-2016). Universidad y Sociedad, 11(4), 377-384.

(14) Dissart, J. (2003). Regional economic diversity and regional economic stability: research results and agenda. International Regional Science Review, 26(4), 423-446.

(15) European Central Bank (ECB). (2021). Economic Diversity. Frankfurt: European Central Bank. www.ecb.europa.eu/mopo/eaec/diversity/html/index.en.html.

(16) Fajnzylber, F. (1983). La Industrialización trunca de América Latina. Ed. Nueva Imagen, México. Pp. 430. https://repositorio.cepal.org/handle/11362/43130

(17) Fujita, M., Krugman, P. \& Venables, A. (2000). Economía espacial. Las ciudades, las regiones y el comercio internacional. Barcelona, España: Ariel Economía.

(18) Guisán, M. y Cardim-Barata, S. (2003). Industria y desarrollo regional en Brasil. Estudios Económicos Regionales y Sectoriales, 3(1), 99-122. 
(19) Heilig, G. (2006). Many Chinas? The economic diversity of China's provinces. Population and Development Review, 32(1), 147-161. https://doi.org/10.1111/j.17284457.2006.00109.x

(20) Hoff, K. y Stiglitz, J. (2002). La teoría económica moderna y el desarrollo. En Meier, Gerald y Stiglitz, Joseph (editores): Fronteras de la economía del desarrollo. El futuro en perspectiva. México, D.F.: Alfaomega-Banco Mundial. Pp. 390.

(21) Jama, V. y Cornejo, J. (2016). Las condiciones socioeconómicas y su influencia en el aprendizaje: un estudio de caso. Revista Dominio de las Ciencias, 2(1), 102-117.

(22) Krugman, P. (1998). What's new about the New Economic Geography? Oxford Review of Economic Policy, 14(2), 7-17.

(23) Lucas, R. E. (1988). On the mechanics of economic development. Journal of Monetary Economics, 22, 3-42.

(24) Mendieta, R. \& Pontarollo, N. (2016). Territorial growth in Ecuador: the role of economic sectors. Romanian Journal of Economic Forecasting. XXI(1). 124-139. https://ipe.ro/rjef/rjef1_18/rjef1_2018p124-139.pdf

(25) Merchand, M. A. (2007). Teorías y conceptos de economía regional y estudios de caso. Centro Universitario de la Costa, Universidad de Guadalajara.

(26) Molero, L. (2014). Convergencia en producto per cápita: Evidencia para Suramérica. Revista de Ciencias Sociales, XX(4), 692-705. 10.31876/rcs.v20i4.25698.

(27) Moncayo, E. (2003). Nuevas teorías y enfoques conceptuales sobre el desarrollo regional: ¿hacia un nuevo paradigma? Revista de Economía Institucional, 5(8), 32-65.

(28) Mora, O. (2006). Las teorías del desarrollo económico: algunos postulados y enseñanzas. $\begin{array}{llll}\text { Revista Apuntes } & \text { del }\end{array}$ https://www.redalyc.org/pdf/4795/479548749004.pdf

(29) Myrdal, G. (1957). Economic theory and underdeveloped regions. London: Gerald Duckworth.

(30) North, D. (1955). Location theory and regional economic growth. Journal of Political Economy, 63(3), 243-258.

(31) North, D. (1990). A transaction cost theory of politics. Journal of Theoretical Politics, 2(4), $355-367$. 
(32) Pede, V. (2013). Diversity and regional economic growth: evidence from US counties. Journal of Economic Development, 38(3), 111-127.

(33) Piore, M. y Sabel, C. (1993). La segunda ruptura industrial. Buenos Aires, Argentina: Alianza.

(34) Plummer, P., Tonts, M. \& Argent, N. (2017). Sustainable rural economies, evolutionary dynamics and regional policy. Applied Geography, 30(2017), 1-13.

(35) Porter, M. (1998). On Competition. Boston: Harvard Business School Press.

(36) Prebisch, R. (1950). The Economic Development of Latin America and its Principal Problems. United Nations, ECLA; also published in Economic Bulletin for Latin America, 7, $1-22$.

(37) Raupp, E. \& Raupp, V. (2018). Dictionary of economic terms. Great Bay Community College Portsmouth, New Hampshire: Blue Impala.

(38) Rello, F. y Saavedra, F. (2013). Diversificación productiva y transformación estructural en México: estudios de caso de tres regiones. Investigación Económica, 72(284), 111-129.

(39) Romer, P. (1986). Increasing returns and long run growth. Journal of Political Economy, 94, 1002-1037.

(40) Rosales, S. y López, S. (2008). Base exportadora y sistema de innovación regional. El caso de Sinaloa. Región y Sociedad, 20(43), 163-187.

(41) Rostow, W. W. (1960). The Stages of Economic Growth: A Non-Communist Manifesto. Cambridge, United Kingdom: Cambridge University Press.

(42) Siegel, P., Johnson, T. \& Alwang, J. (1995). Regional economic diversity and diversification. Growth and Change, 26, 261-284.

(43) Silveira, M. (2007). Diferencias regionales en el territorio brasileño: perspectiva diacrónica y sincrónica. Scripta Nova, 11(244). http://www.ub.edu/geocrit/sn/sn-244.htm

(44) Solow, R. (1956). A Contribution to the theory of economic growth. Quarterly Journal of Economics, 70(1), 65-94.

(45) Urdaneta, A. y Borgucci, E. (2021). Economías de aglomeración y externalidades negativas en Ecuador, periodo 2007-2017. Cuadernos de Economía, 40(82), 165-192. https://doi.org/10.15446/cuadecon.v40n82.81058

(46) Veltz, P. (1996). Mondialisation villes et territoires, L'Économie d'archipel. París: Pressses Universitaires de France. 
(47) Wagner, J. (2000). Regional economic diversity: action, concept, or state of confusion. The Journal of Regional Analysis and Policy, 30(2), 1-22.

(48) Williamson, O. (1985). The Economic Institutions of Capitalism: Firms, markets, relational contracting. Free Press. New York.

Cómo citar este artículo: Izquierdo, W. y Carangui, P. (2021). Diversidad económica regional y desempeño socioeconómico en las provincias del Ecuador (período 2014-2018). Tendencias, 23(1), 87-116. https://doi.org/10.22267/rtend.222301.184 